
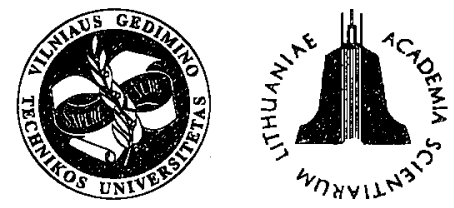

ISSN 1648-4142 TRANSPORT

http:/www.vtu.lt/english/editions

TRANSPORT - 2003, Vol XVIII, NO 3

\title{
THE REVIEW OF THE MONOGRAPH "TRANSPORT SYSTEM: MODELS OF DEVELOPMENT AND FORECAST"* (BY ADOLFAS BAUBLYS)
}

Major factors determining global economic development are the integration processes taking place now at all levels in Europe. They are aimed at the creation of the common European space.

Under these conditions, the role of transport as a universal technology of the early 21 - st century is particularly great. The creation of unified transport networks and the development of multimodal systems as welf as the changing paradigms of transport systems, which are becoming more oriented at the humans, their needs and at the environment, require a thorough analysis of the current development trends of transport as a complicated system functioning in constantly changing conditions. On the other hand, new models of transport systems which could be adapted to global changes taking place in Europe are needed.

The above problem becomes even more urgent in view of the dynamically changing economic relations in Europe because of the integration of new states into the European Union. This raises new research problems for the states candidates which should adapt the processes taking place in their life and economy to the predicted global short - term and long - term European development.

In this context the monograph reviewed, where methodological problems of the analysis and forecast of transport development are considered by using a system approach, is undoubtedly valuable and timely.

In his book the author provides major characteristics of the development of the unified European transport system describing the actual role of his country in the global processes of the division of labour based on the economic analysis and suggests a number of original approaches, models and techniques for the analysis and forecasting of the development of transport system as a constituent of the above global process.

The monograph consists of the introduction, six sections and references.

The Introduction presents a general conceptual model of the monograph and gives brief descriptions of each section.

Section 1 prcvides the analysis of the problems characteristic of the transport sector of Lithuania associated with its restructuring in the period of the country's integration into the European Union (EU). The review of major trends and prospects of development of the above field of economy is provided. The emphasis is laid on the analysis and the trends of development of transport infrastructure in the context of its integration into the unified trans - European network.

The introduction of the above strategies is illustrated by the analysis of numerous investment projects aimed, primarily, at the development of transport corridors through the territory of Lithuania. Lithuania piays an important role in the integration of the railroads into a unified European network. In this respect the analysis of the implementation of the EU Directive concerning the railroad sector in Lithuania as well as the description of long - term national strategies in transport are of special interest.

In Section 2, the approaches to the analysis of national transport in terms of the theory of large systems are described. Major parameters of the above systems as well as the methods of analysis and research problems associated with this class of systems are defined. In the monograph the emphasis is placed on the control of the systems and the need for involving both technological and analytical attributes in the description of decision - making procedure, taking into account sophisticated hierarchic structure of the system. The key issue of the section is the description of research and methodological goals of transport models analysis in terms of the theory of large systems and their application with account of the research goals as well as freight transportation development in Lithuania.

\footnotetext{
* A. Baublys. Transport System: Models of Development and Forecast. Vilnius: Technika, 2003. 208 p. ISBN 9986-05-606-3
} 
Section 3 deals with the problems of forecasting the volume of freight and passengers transportation. Methods of forecasting based on multidimensional regression and correlation analyses are presented. The procedures of choosing linear or non - linear mathematical models, depending on the empirical data available, are described.

In Section 4, the influence of numerous random factors of the actual process of transportation on freight transportation is determined. The classification of random factors is given for the hierarchic structure of technological process of transportation.

The variation of the above factors, depending on statistics and cost factors, is analysed. The problems of storage of the statistical data and mathematical models involved are also discussed.

Section 5 describes the models of freight transportation development, taking into account the geopolitical role of Lithuania in providing the transit North - South, West - East corridors. Major factors determining the development of the transport system and access to the services it provides are outlined. Special attention is paid to the interaction of the particular transport facilities and the interface models of this interaction. Static and dynamic models of transport network development are also described.

The analysis of the models of private transport development is particularly interesting in view of the privatization processes taking place in transport.

Section 6 presents a description of a set of probability models used solving management problems of the park of motor vehicles. The models for analysing the flow of failures and the reconditioning flow with respect to transport facilities of the park, and the stochastic models for making safety forecasts based on the data provided are also described. Numerous examples illustrating practical application of the models and algorithms offered by the author are of great value.

In general, the reviewed monograph presents a complete original investigation. One of its merits is the topicality of the problems considered with respect to practical needs of transport systems at the national level and methodology, due to the application of approaches based on the use of the analytical models for the study and forecast of transport development.

The research of transport problems is continually changing, with the structure and trends of investigation not being definitely outlined. In this respect the effort of the author to present his original view of the problems is of great interest.

The book may be recommended for researchers involved in system analysis of transport and for decision makers, determinining the strategies and policies of transport development.

The monograph may also be useful for undergraduates and doctoral students of transport specialities in universities and institutes of the above profile.

Vytautas Paulauskas,

Prof Habil Dr of Sciences 